\title{
Towards a Cultural-Clinical Psychology
}

\author{
Andrew G. Ryder ${ }^{1,2}$, Lauren M. Ban ${ }^{1,2}$, and Yulia E. Chentsova-Dutton ${ }^{3}$ \\ ${ }^{1}$ Concordia University \\ ${ }^{2}$ Sir Mortimer B. Davis-Jewish General Hospital \\ ${ }^{3}$ Georgetown University
}

\begin{abstract}
For decades, clinical psychologists have catalogued cultural group differences in symptom presentation, assessment, and treatment outcomes. We know that 'culture matters' in mental health - but do we know how it matters, or why? Answers may be found in an integration of cultural and clinical psychology. Cultural psychology demands a move beyond description to explanation of group variation. For its part, clinical psychology insists on the importance of individual people, while also extending the range of human variation. Cultural-clinical psychology integrates these approaches, opening up new lines of inquiry. The central assumption of this interdisciplinary field is that culture, mind, and brain constitute one another as a multilevel dynamic system in which no level is primary, and that psychopathology is an emergent property of that system. We illustrate cultural-clinical psychology research using our work on depression in Chinese populations and conclude with a call for greater collaboration among researchers in this field.
\end{abstract}

Horace Cho ${ }^{1}$ is a 57-year-old businessman from Hong Kong who has resided in Vancouver for fifteen years, referred for insomnia, fatigue, loss of appetite, gastrointestinal distress, and depressed mood. Mr. Cho was raised in Hong Kong, completed his MBA in California, and moved to Vancouver to join his wife's family and start a new business. Despite Mr. Cho's excellent English and knowledge of North American practices, his business is in difficulty. He attributes business troubles to the effects of his physical symptoms, rather than seeing these symptoms as resulting from psychosocial stress.

Mr. Cho lives in a majority Chinese suburb and encourages his children to stay close to Chinese traditions; however, his daughters desire greater participation in North American society. He describes his wife as much more traditional than he is, but to his surprise it is she who encourages the children to participate in mainstream society. At the initial interview, Mr. Cho denies depressed mood but agrees that symptoms, business difficulties, and values conflicts in his family are 'upsetting sometimes'.

What is Mr. Cho's 'culture', and is it the same as his wife's? Does he have a mental health problem and, if so, what is it? In what ways does culture shape the experience, expression, and communication of his distress? Where can psychologists look for ways to think about such questions?

Over the past few decades, scholars from several disci-

Correspondence address: PY153-2, 7141 Sherbrooke St. W., Montreal, Quebec, H4B 1R6, Canada. Email: andrew.ryder@concordia.ca plines have examined the interrelation of culture and mental health. Many more have taken on cross-cultural comparisons in mainstream psychology. That 'culture matters' in clinical psychology is nothing new, although it bears frequent repetition in an era of biological reductionism. Rather, our claim is threefold: first, that there is relatively little cultural research in clinical psychology that aspires to explanation, to telling a culturally-framed story about what is observed; second, that the means for achieving this can be found in greater integration of cultural and clinical psychology, to the benefit of both; and third, that the result is a new field. Cultural-clinical psychology has in some sense been around for a while, pursued by a small number of researchers. Nonetheless, it has not yet coalesced as an established field of study or as an approach to culture and mental health research. This paper aims to promote these ends.

We start by locating ourselves with respect to 'cultural psychology' and 'clinical psychology', and then present some first steps toward a cultural-clinical psychology. Central to this integration is the idea of mutual constitution - that culture, mind, and brain form a single system in which no level can be understood without the others. We then draw on our own research, pertaining to depression in Chinese populations, to provide some empirical examples. We conclude with a brief critique of these studies, considering ways in which they could be improved and interpreted in light of cultural-clinical psychology. Concrete suggestions to improve cultural-clinical psychology research are summarized in the Appendix and referenced throughout.

\footnotetext{
${ }^{1}$ Horace Cho is based on a composite of two cases. Identifying information has been fictionalized.
} 


\section{Cultural-Clinical Psychology: A Brief Introduction}

\section{Cultural Psychology}

In positioning cultural-clinical psychology, we begin by grounding the first term in the 'cultural psychology' perspective (e.g., Markus \& Kitayama, 1991; Shweder, 1990). The word 'culture' has long been used in psychology to stand for ethnicity or nationality, and invoked as a black-box explanation: groups differ because of 'culture', but the specific ways in which this happens remain unclear. Cultural psychology represents a move away from cataloguing differences to understanding culture and how it shapes psychological variation (e.g., Betancourt \& López, 1993; Cohen, Nisbett, Bowdle, \& Schwarz, 1996; Heine \& Norenzayan, 2006; Kitayama, Markus, Matsumoto, \& Norasakkunkit, 1997). Differentiating between culture and 'cultural group' emphasizes that individual group members can partially adhere to or reject aspects of culture. For example, Mr. Cho and his wife have different views about the acculturation of their children, and not in ways that are obviously predictable from their own degree of traditionalism (Appendix: 1.1).

Is culture best understood as 'in the head' or 'in the world'? These views are held in tension and they sometimes conflict but, as with cognition and behavior in clinical psychology, neither is sufficient alone. People do not simply carry out behaviors. Rather, they perform 'acts of meaning' (Bruner, 1990), intended by the actor and understood by observers as meaningful. These acts are framed by the cultural meaning system and their enactment contributes to shaping this system (Kashima, 2000). Nisbett and Cohen (1996), for example, conducted an important series of studies on the 'Culture of Honor' in the American South, reporting that southerners have more favorable attitudes towards violence in cases where honor is at stake. Moreover, they demonstrated experimentally that southerners whose honor has been challenged are more physiologically reactive and take longer to step out the way of a confederate walking toward them in a narrow corridor. Cultural variation is captured here by both opinions and behaviors, and the behaviors of both participant and confederate are understood as meaningful.

The idea of cultural scripts can bridge these perspectives, as they both reflect meaning structures in the head and guide behavioral practices in the world (DiMaggio, 1997). Scripts refer to organized units of knowledge that encode and propagate meanings and practices. They serve as mechanisms that allow for rapid automatic retrieval and use of information acquired from the world while shaping how that information is perceived. Enacted as behavior, scripts are observable to others and become part of the cultural context, shaping assumptions about what others think and expectancies about how they will behave (Chiu, Gelfand, Yamagishi, Shteynberg, \& Wan, 2010). Moreover, people can access multiple cultural scripts, primed by different contextual cues (Hong \& Chiu, 2001). If while at home Mr. Cho scolds his children for pursuing a 'Western lifestyle', he is accessing available scripts for cultural preservation while his actions and others' responses contribute to shaping these scripts, and passing them to his children. In work contexts, these same scripts may be primed rarely if at all. Mr. Cho's wife can understand him according to their shared meaning system even as she accesses a different available cultural script - promoting her children's well-being by ensuring they can function in a new society (Appendix: 2.2).

\section{Clinical Psychology}

In using the term 'clinical' in cultural-clinical psychology, we are thinking primarily of researchers trained as scientists or scientist-practitioners in clinical psychology, health psychology, or experimental psychopathology. Although not all of these researchers are directly engaged with both science and practice, there is an emphasis on moving between theory and research about groups on the one hand, and the experiences and needs of individual sufferers on the other. Clinical psychology is concerned both with describing pathological phenomena and with using psychological principles to intervene with these phenomena therapeutically.

As a health discipline, clinical psychology inevitably discusses 'symptoms' and 'syndromes' - specific pathological experiences and the ways in which they are grouped. $\mathrm{Mr}$. Cho's reported symptoms are insomnia, fatigue, loss of appetite, and gastrointestinal distress, with some evidence of depressed mood. A clinician trained in DSM-IV has over 300 syndromes to consider, but would most likely consider Major Depressive Disorder (MDD). Clinical psychology has long had a certain willingness to critique diagnostic systems accompanied by a preference for evidence-based symptom dimensions (Achenbach \& Edelbrock, 1983; Krueger \& Markon, 2006). This openness benefits cultural studies of psychopathology, as diagnostic systems are themselves cultural products (Gone \& Kirmayer, 2010; Lewis-Fernández \& Kleinman, 1994). Moreover, Kleinman (1988) argues that rigid application of a diagnostic system conceals cultural variation. He has shown how The International Pilot Study of Schizophrenia reliably identified patients meeting diagnostic criteria for schizophrenia, but in doing so eliminated a large proportion of psychotic patients at each site - precisely those patients who showed the most variability across the cultural groups (Appendix: 1.2).

\section{Cultural-Clinical Psychology: What's New?}

In an era both of fragmentation and interdisciplinarity in psychology (Cacioppo, 2007) it is easy to argue that two areas can benefit from collaboration on topics of shared concern. We wish to make a stronger claim in this case: a new field emerges at their intersection. For this to be plausible, we 
must first establish that clinical psychology is altered by consideration of cultural questions. More challenging, we must also establish that cultural psychology is altered by clinical questions, not simply given new content. Research in cultural-clinical psychology should tell us something new about the cultural contexts under study, not just the pathologies. Finally, we must demonstrate that new questions and methods for addressing them emerge from this sub-discipline, or at least that the potential is there (Appendix 2.1).

\section{Clinical Psychology Encounters Cultural Psychology}

A central issue for clinical psychology - what is disorder? - cannot be fully understood without considering deep cultural influence. The oft-used distinction between illness and disease defines illness as the socially-situated experience of having a particular disorder and disease as the corresponding malfunction in biological or psychological processes (Boorse, 1975; Kleinman, 1977). Wakefield (1992) similarly defines disorder as harmful dysfunction, in which harm indicates that the disorder is problematic in a given cultural context and dysfunction indicates the failure of a biological system evolutionarily adapted for particular ends.

While these approaches ostensibly give equal credit to culture and biology, uncritical acceptance plays into biases of mainstream clinical psychology. Researchers can end up exemplifying Geertz's (1984, p. 269) characterization of the behavioral sciences, in which, "culture is icing, biology, cake... difference is shallow, likeness, deep". We prefer to see disorder as both biological and cultural, in a fundamentally inseparable way. Depressed mood has many biological and cultural constituents worthy of focused study for specific purposes, but there is no depressed mood until these constituents come together and are experienced by someone.

Methodologically, clinical research has much to gain from incorporating the cultural psychology perspective. Integration of findings on the cultural shaping of psychological functioning can allow clinical psychologists to develop a broader and more nuanced view of normal human experience. Cultural psychology is well positioned to help clinical psychology move beyond conceptualizations of mental illnesses as products of solitary minds to thinking of it as contextually embedded in networks of local meanings, norms, institutions, and cultural products (e.g., Adams, Salter, Pickett, Kurtis, \& Phillips, 2010). Finally, cultural psychology can inform our understanding of the ways in which people, including both patients and clinicians, incorporate contextual information in detecting, reporting and interpreting symptoms of mental illness (for examples of these cultural psychology ideas, not yet adapted for clinical questions, see Heine, Lehman, Markus, \& Kitayama, 1999; Hong, Morris, Chiu, \& Benet-Martínez, 2000; Masuda \& Nisbett, 2001; Uchida, Norasakkunkit, \& Kitayama, 2004). In Mr. Cho's case, the institutional demands of a mental health clinic may have tilted the emphasis toward symptoms and attributions and away from the understandable suffering caused by business and family difficulties (Appendix: 2.3).

The idea of scripts can help us think about specific ways in which mental health is shaped by cultural context. Although by definition abnormality violates expectations of what is normal, people nonetheless have scripts to help them make sense of pathology as best they can. Confusing and frightening experiences, such as emerging psychopathology, have a particularly strong need for scripts (Philippot \& Rimé, 1997; Taylor, 1983). The large but finite number of ways to be physically or psychologically distressed is further molded by cultural-historical context, so that specific disorders draw upon a pool of available symptoms (Shorter, 1992). Cultural scripts can then be seen as mapping the sufferer's experience to what is available in this 'symptom pool', focusing on and thereby amplifying those symptoms that best serve explanatory and communicative purposes. Denial of depressed mood and acknowledgement that his problems are upsetting can be seen as serving Mr. Cho's communication goals in a particular health care setting.

\section{Cultural Psychology Encounters Clinical Psychology}

Beyond providing new content, potential contributions of clinical psychology begin with two of cultural psychology's core concerns: heterogeneity of cultural groups and limited coherence of cultural contexts (Kashima, 2000). These concerns do not necessarily require clinical psychology, but the study of mental disorder serves as an engine to generate many examples of each. Psychopathological phenomena also shed new light on culture; as with the lesion studies that propelled neuroscience, we learn new things about cultural processes when the normal cultural scripts no longer work (for a similar idea, not specific to psychopathology, see Beckstead, Cabell, \& Valsiner, 2009). North American studies of social phobia patients highlight the central role fear of negative evaluation plays when healthy interpersonal functioning breaks down (see Hofmann \& Barlow, 2002). These findings also reveal some of the assumptions of normal social relationships in North America: one is to portray one's true self and have it be positively evaluated by others. Studies of socially anxious patients in other cultural groups can serve the same function, showing for example how fear of causing discomfort to others - perhaps by inappropriately revealing one's true self - is a central concern for many socially anxious people in East Asian contexts (Rector, Kocovski, \& Ryder, 2006; Sasaki \& Tanno, 2005; Zhang, Yu, Draguns, Zhang, \& Tang, 2000).

Methodologically, clinical psychology has a rich tradition of modeling ways in which abnormal behavior is shaped by constraints imparted by physiological and environmental influences, and their interactions. For example, contemporary research on depression spans multiple levels of analysis rang- 
ing from genes to hormones, brain anatomy and function, attention, memory, emotional reactivity, personality, and interpersonal functioning (Hammen, 2003; for a thorough review, see chapters in Gotlib \& Hammen, 2009). Clinical psychology can also provide tools for theorizing about the ways in which psychological processes become functional or dysfunctional in a cultural context. For example, cultural innovation and propagation depends on specific abilities, such as harnessing novel associations or conveying negative emotions (Chentsova-Dutton \& Heath, 2007), that are also associated with predisposition to certain forms of psychopathology.

\section{Cultural-Clinical Psychology: Mutual Constitution of Culture-Mind-Brain}

The core claim of cultural psychology is not simply that groups differ or 'culture matters', but rather that human culture and human psychology are each grounded in the other: that culture and mind 'make each other up' (Shweder, 1991). Clinical psychology research, in keeping with trends in psychological science and in psychiatry, tends to focus more on the interrelation of mind and brain (Andreasen, 1997; Barrett, 2009; Ilardi \& Feldman, 2001). We argue that the best approach for cultural-clinical psychology emerges from the joint concerns of the two fields, leading us to discuss mutual constitution of culture, mind, and brain. This approach follows recent trends in cultural psychiatry (Kirmayer, 2012) and cultural psychology (Chiao, 2009; Kitayama \& Park, 2010; Kitayama \& Uskul, 2011), in which culture, mind, and brain are thought of as multiple levels of a single system, here called the culture-mind-brain (Appendix 3.1).

\section{Culture and Mind}

The mutual constitution of culture and mind develops through processes that are an integral part of socialization, in that minds develop in cultural contexts that are themselves composed of minds (Cole, 1996; Valsiner, 1989). We cannot understand human minds unless we understand them in cultural context, and we cannot understand human culture unless we understand minds. The goal is to find ways of thinking and studying the psychological and the cultural so that neither is seen as the ultimate source of the other (Markus \& Hamedani, 2006; Shweder, 1995).

\section{Mind and Brain}

It is increasingly untenable to propose models of mental health that have no room for the brain, as shaped by the genome and in turn by evolutionary processes. While we agree wholeheartedly with Geertz (1973) that, "it is culture all the way down", we also simultaneously make the opposite claim: it is biology all the way up. Both must be true for mutual constitution to have any meaning. Rather than seeing mind as the subjective epiphenomenon of brain, however, we prefer a view of mind as fundamentally social and tool-using, even as extended beyond the brain (Clark \& Chalmers, 1998; Hutchins, 1995; Kirmayer, 2012; Vygotsky, 1978). Habitually used tools and close others are partially incorporated into one's mind: the online calendar can become part of the mind's memory system; the close friend can become part of the mind's emotion regulation system.

\section{Culture and Brain}

It does not necessarily follow from a tripartite model of culture, mind, and brain in this way that mind mediates all culture-brain links. The human brain is adapted to acquire culture and responds to cultural inputs with marked plasticity, especially early in development (Wexler, 2006). Indeed, the emergence of a recognizable human mind may require these transactions between culture and brain. At the same time, biology constrains culture. There are a large number of possible ways in which culture can be configured, yet the number of impossible configurations is practically infinite (Gilbert, 2002; Mealey, 2005; öhman \& Mineka, 2001). That this is true does not compromise the equally important observation that human possibilities are many, diverse, and deeply shaped by culture (Marsella \& Yamada, 2010; Tseng, 2006).

\section{The Ecology of Culture-Mind-Brain}

Describing the interrelations of culture, mind, and brain as a triangle of linked associations might imply three interrelated systems. We prefer to think of culture-mind-brain as one dynamic multilevel system, an information network instantiated in neuronal pathways, cognitive schemata, human relationships, culturally-mediated tools, global telecommunications, corporations, political actors, health care systems, and so on. Cultures, minds, and brains cannot be understood in isolation from one another. As yet, there is little research that engages with all three levels simultaneously, although a promising avenue has been opened by Kim, Sherman, Taylor, et al. (2010a). These researchers showed that cultural context and variations in certain serotonin receptor genes interact to predict locus of attention. Specifically, one of the variants predicts a tendency to attend to context in Korean participants, and the same variant predicts an especially strong tendency to attend to the focal object in Euro-American participants.

Psychopathology is an emergent property of culture-mind-brain, with no ultimate cause at any one level. While changes at one level affect all levels, it does not follow that disorder at one level means disorder at other levels, let alone that disorder at a higher level must be caused by disorder at a lower level. A disordered brain circuit does not require malfunctioning neurons, nor does a disordered neuron require malfunctioning molecules, although neither makes 
sense in the absence of neurons or molecules. Pathology can emerge from problematic feedback loops in which the response to a problem exacerbates the problem, even when all components of the loop are working normally (Hacking, 1995; Kirmayer, 2012). A conditioned fear that goes on to cause problems in living is a disorder, it involves the brain, but it does not require a disordered brain. Values conflict between Mr. Cho and his wife can create a stressful environment for their children, but not because a lower-level disorder leads them to adhere to pathological values.

Disorder at higher levels can also lead to disorder at lower levels. Cultural norms, economic conditions, and political response might interact to produce violent conflict, with consequences that include damage to brains from traumatic stress. It is incomplete at best to claim that psychological consequences of that damage are caused by the brain without acknowledging political or economic causes. Similarly, Mr. Cho's depression might make sense as psychosocial stress coupled with preexisting vulnerability, but the depression has lasting consequences for the brain (Kendler, Thornton, \& Gardner, 2000). A mind-level intervention such as Cognitive-Behavior Therapy (CBT), moreover, impacts on the brain (DeRubeis, Siegle, \& Hollon, 2008) - unsurprising, as culture-mind-brain is a single system (Appendix 3.2).

Before considering an example of three recent cultural-clinical psychology lines of research focused on an interrelated set of questions, let us briefly return to the case of Mr. Cho.

After the initial assessment, Mr. Cho began a 16-week course of CBT for depression. The case at first appeared to be a textbook case of 'Chinese somatization'; somatic symptoms were discussed almost exclusively, unlinked to psychosocial stressors. Sustained discussion of these stressors would sometimes lead to marked tearfulness and inability to maintain emotional composure. Once rapport was established, depressed mood was acknowledged fairly quickly, along with guilt and pessimism, primarily described as reactions to how the physical symptoms had impacted his business and family life.

Mr. Cho asked several times how CBT could help him with his primary concern - the somatic symptoms - and as treatment turned to depressed mood, guilt, and pessimism, he began to miss sessions. We reframed treatment in line with CBT approaches to Chronic Fatigue Syndrome - emphasizing holism of mind and body, talking more openly about somatic symptoms, and incorporating some somatic approaches such as sleep hygiene and diet regulation. Psychological and physical causes, psychological and physical symptoms, all became legitimate topics for discussion.

\section{Cultural Psychology: Empirical Examples}

We are each involved in independently developed lines of research taking a cultural psychology approach to clinically- relevant questions about Chinese-origin participants and depression. To illustrate the potential of cultural-clinical psychology, we turn to a more sustained discussion of this work.

\section{Cultural Psychology Research on Depression}

\section{Somatic and Psychological Symptoms}

In a now classic study, Kleinman (1982) argued that Chinese psychiatric patients tend to emphasize somatic symptoms relative to 'Western' norms (see also Parker, Cheah, \& Roy, 2001). Ryder et al. (2008) used multiple assessment methods with Han Chinese and Euro-Canadian psychiatric outpatients. Results generally showed greater somatic symptom reporting in the Chinese group and greater psychological symptom reporting in the Euro-Canadian group. The tendency to devalue the importance of one's emotional life was also higher in the Chinese group and mediated the relation between cultural group and symptom presentation.

Devaluation of one's emotional life does not fit well with readily accessible cultural scripts in North America. This tendency was measured using a tool designed to measure pathology, the Externally-Oriented Thinking (EOT) subscale of the Twenty-item Toronto Alexithymia Scale (TAS-20; Bagby, Parker, \& Taylor, 1994). Whereas EOT might capture pathological beliefs in a cultural context that fosters ideals of healthy emotional expression, it may simply represent adherence to an accessible cultural script in Chinese contexts (see Dion, 1996; Kirmayer, 1987). In a comparison of Chineseand Euro-Canadians, group difference in EOT was mediated by adherence to 'Western' values (Dere, Falk, \& Ryder, 2012). People vary in accessibility of cultural scripts about emotional expression, and cultural contexts vary in terms of how normal these scripts are perceived to be. Mr. Cho had access to multiple scripts but the Chinese somatic script predominated - he emphasized somatic symptoms while increasingly considering psychological symptoms, and tended to see the latter as consequences of somatic symptoms.

\section{Emotional Expression}

Studies comparing depressed Euro-Americans and AsianAmericans to their non-depressed counterparts show that depression is associated with culturally-specific patterns of emotional reactivity. For Euro-Americans, depression is characterized by dampened emotional reactivity in response to positive and negative emotional films (see Bylsma, Morris, \& Rottenberg, 2008). Chentsova-Dutton et al. (2007) replicated this pattern with negative films in Euro-Americans using self-report, facial coding, and physiological measures, but failed to find it - and at times, found the inverse in Asian-Americans (primarily Chinese-Americans). More surprisingly, Chentsova-Dutton, Tsai, and Gotlib (2010) replicated the pattern using positive films, so that on certain measures such as cardiac reactivity, depressed Asian- 
Americans were actually more reactive than non-depressed Asian-Americans.

Cultural contexts provide people with shared scripts for how to feel and express emotions. Failure to enact culturally normative emotional scripts may contribute to depressed mood, and may also be exacerbated by such mood. The Euro-American pattern of dampened reactivity when depressed may reflect failure to enact accessible cultural scripts for open and prominently displayed emotional responses (Bellah, Sullivan, Tipton, Swidler, \& Madsen, 1985). The Chinese-American pattern of heightened reactivity when depressed may reflect failure to enact readily available cultural scripts of moderated experience and expression of one's emotions (Russell \& Yik, 1996). Exemplifying the latter, Mr. Cho was at times strikingly expressive discussing difficult topics despite retrospectively denying depressed mood.

\section{Explanatory Models}

It is normative in 'Western' cultural settings to not just emphasize psychological symptoms but also to link distress to psychological causes. Ban, Kashima, and Haslam (2010) explored the extent to which behavior is deemed pathological if it violates this cultural script. A vignette describing someone with depression, including or not including a psychological cause, was presented to Euro-Australian and Chinese-Singaporean university students. Euro-Australian students were more likely to perceive depression as 'normal' when their vignette included a psychological explanation. For Chinese-Singaporean students, psychological explanations made the depression seem less normal, and they preferred moral to psychological explanations on a questionnaire.

For Euro-Australians, living in a cultural context with a readily accessible script equating abnormality with irrational psychological functioning, psychological explanations help restore a sense of order. Chinese-Singaporeans, by contrast, live in a cultural context where the predominant script equates emotional maturity with adjustment of behavior to situational demands (Kirmayer, 2007). Indeed, ChineseSingaporean moral explanations centered on failed social obligations. These modes of explanation represent scripts that are available, to varying extents, in different cultural contexts. Mr. Cho initially presented along the lines of a medicalizing script, which soon gave way to a moralizing script about failing his family. Eventually, he was willing to consider a psychologizing script without fully endorsing it.

\section{Reinterpreting the Research}

How can we understand these findings in light of culture-mind-brain? Before depression emerges, people have access to culturally shaped scripts about what depression is and assume others have access to these scripts as well (Ban et al., 2010). Once depression emerges, its implications cascade rapidly through all levels of culture-mind-brain, motivating people to make sense of what is happening to them (Philippot \& Rimé, 1997). Scripts focus attention on certain symptoms, magnifying some experiences and minimizing others. A looping effect takes place - experiences that best draw upon the cultural symptom pool in ways that fit available scripts about depression are focused upon, further contributing to their severity (Shorter, 1992). Multiple cultural scripts can coexist and draw upon this pool, so that patients in a single cultural context can nonetheless present many different kinds of symptoms (Ryder et al., 2008).

In keeping with the idea of mind as social, we have real and imagined audiences for this process: what do we tell other people; what are they going to notice; how are they going to react? (Chiu et al., 2010) These others are specific others, with their own experiences, relationships with the sufferer, social roles, and functions within societal institutions. The real and imagined presence of specific others shapes the explanations chosen, the emotions expressed, and the symptoms emphasized (Chentsova-Dutton \& Tsai, 2010; Jakobs, Manstead, \& Fisher, 1996; Lam, Marra, \& Salzinger, 2005; Matsumoto, Takeuchi, Andayani, Kouznetsova, \& Krupp, 1998). Sufferers generate additional stressors as others react to evident and unusual signs. It is not simply that depression is associated with non-normal emotional expressions (Chentsova-Dutton et al., 2007, 2010), but that another loop is generated where reactions of others to these expressions lead to censure and withdrawal, hence to rejection and further depression.

As per the cultural dynamical approach (Kashima, 2000), we should expect actual experiences of depression - what is experienced, expressed, talked about, witnessed, shared with mental health professionals, discussed in the local community - to shape cultural scripts pertaining to depression. There is emerging evidence in China that rapid social change is shifting public understanding of depression, altering cultural scripts, and in turn shaping symptoms presented by successive cohorts. In consequence, exposure to modernization and Westernization values is lessening the tendency for Chinese patients to emphasize somatic symptoms of depression (Ryder et al., 2011).

\section{Contributions and Limitations}

These studies represent three independent attempts to bring together cultural and clinical psychology to investigate a particular clinical phenomenon in a particular cultural group, drawing on both fields for theory, methodology, and interpretation. These studies go beyond cataloguing group differences, examining how various aspects of Chinese - and 'Western' - cultural contexts, including scripts, values, cognitive styles, norms, and attributions, shape depression. They are methodologically varied, including self-report question- 
naires but also interviews, open-ended response coding, psychophysiology, facial coding, vignettes, mediation analysis, and experimental designs.

Our studies have limitations, notably including failures to adhere to some of the recommendations summarized in the Appendix. Cultural and diagnostic groups, for example, could be more clearly defined. The studies are compatible with a dynamic view of culture but do not go very far in advancing that agenda. Culture is not assessed in a multimethod way. More fundamentally, however, what is missing so far is the brain, and thus the potential synthesis implied by culture-mind-brain. Somatic and emotional experiences are connected in the brain (Craig, 2008) and may be emphasized or deemphasized in the mind based on cultural scripts (Wiens, 2005). Kim, Sherman, Sasaki, et al. (2010b) have shown that variations in oxytocin receptor genes interact with cultural context and level of subjective distress to predict help-seeking, a rare example of how levels of culture-mind-brain can be included in a single study.

Even with improvements in conception, sampling, methods, and interpretation, we do not expect that any given study, or even research program, would cover everything discussed here. Cultural-clinical psychology already exists in a sense, including researchers who have been making important contributions for years. At the same time, there is as yet little sense of a shared enterprise, let alone of the institutional markers of such. What is needed is a greater degree of coherence and integration, where individual research groups approach different pieces of the overall puzzle, but with a shared framework and an ongoing commitment to putting this puzzle together.

\section{Conclusion}

There is much to be gained from greater connection between cultural and clinical psychology, with a core of researchers at the intersection. Cultural psychology can benefit from testing the limits of cultural influence across the full range of psychological functioning, including psychopathological extremes and difficult environmental conditions. Likewise, clinical psychology can consider a wider range of sociocultural phenomena that may affect mental illness. The two fields together point to a dynamic model of culture-mind-brain that can serve as a central pillar of this interdisciplinary field. Cultural-clinical psychology advances attempts to conceptualize mental health phenomena as dynamic and context-dependent, rather than fully reducible to physiological deficits or environmental stressors. We emphasize 'cultural' aspects because we believe that explanations at this level are often neglected in mental health research, but hope that ultimately no discussion of mental health will seem complete without consideration of all levels.

The case of Mr. Cho illustrates how knowledge of cultural context and its accessible symptom scripts help us to bet- ter assess clients and modify treatment approaches to better adapt to these scripts. We observe how the clinical encounter becomes a space in which cultural scripts are negotiated, influencing both participants and shifting over the course of treatment. Training programs, internship sites, and licensing bodies increasingly insist on training in diversity and cultural competence without a clear vision of how to proceed or what evidence to use. Cultural competence is more than simply using good clinical skills with ethnic minority patients; cultural-clinical psychology can aspire to provide an evidence base (Ryder \& Dere, 2010). At the same time, cultural competence includes questioning that evidence, considering dangers of reducing people to cultural categories (Kleinman \& Benson, 2006). As we conclude our case history, we catch a glimpse of how seeing a patient's symptoms only through the lens of cultural explanations can yield surprises.

By the end of treatment, Mr. Cho was still struggling but wanted to try implementing some changes by himself. He continued to prioritize somatic symptoms, but agreed that psychological symptoms were part of his experience. At six-month follow-up, Mr. Cho reported ongoing appetite and gastrointestinal problems, but much better sleep, energy level, and mood. He mentioned that he was now working with a specialist, who was finding that the ongoing gastrointestinal and appetite problems might be related to a specific medical issue. The possibility of this separate issue may have been lost in the context of the other symptoms.

\section{Acknowledgement}

Preparation of this manuscript was supported by a New Investigator Award from the Canadian Institutes of Health Research to AGR. The authors gratefully acknowledge the comments provided by Emily Butler, Jessica Dere, Marina Doucerain, Alan Fiske, MarYam Hamedani, Nick Haslam, Steve Heine, Tomas Jurcik, Yoshi Kashima, Laurence Kirmayer, Michael Lorber, Andrea McCarthy, Vinai Norasakkunkit, Nicole Stephens, and Romin Tafarodi on earlier versions of this manuscript.

\section{Short Biographies}

Andrew G. Ryder received his doctorate in psychology (clinical) from the University of British Columbia and currently directs the Culture, Health, and Personality Lab in the Department of Psychology at Concordia University, where he holds the position of Associate Professor. He is also an adjunct faculty member in the Culture and Mental Health Research Unit at the Sir Mortimer B. Davis-Jewish General Hospital in Montreal. Dr. Ryder's research lies at the intersection of cultural, clinical, and personality psychology. Most of his published work combines at least two of these areas, including papers in Journal of Abnormal Psychology, Harvard Review of Psychiatry, Journal of Affective Disorders, Journal of Personality and Social Psychology, and 
Journal of Personality Disorders. Current research focuses on: (a) the intersection of cultural and personality variables in shaping depressive symptom presentation in China and South Korea; and (b) acculturation and adaptation in complex multicultural societies. His work is supported by a New Investigator Award from the Canadian Institutes for Health Research (CIHR) and grants from CIHR and the Fonds de la recherche en santé du Québec.

Lauren M. Ban received her doctoral degree in psychology (social) from the University of Melbourne. At time of writing she was a postdoctoral fellow in the Department of Psychology at Concordia University and the Culture and Mental Health Research Unit at the Sir Mortimer B. Davis-Jewish General Hospital in Montreal, under the supervision of Dr. Ryder and Dr. Laurence Kirmayer. Her dissertation research explored folk perceptions of mental disorder comparing people with East Asian (primarily Chinese-Singaporean) and European-Australian cultural backgrounds, and a study from this work has been published in the Journal of Cross-Cultural Psychology. Current research takes a cultural psychology perspective on self-construals, explanatory models of mental illness and internalized stigma.

Yulia E. Chentsova-Dutton received her master's degree (clinical science and psychopathology) from the University of Minnesota and her doctoral degree (affective science) from Stanford University. She holds the position of Assistant Professor in the Department of Psychology at Georgetown University in Washington, D.C., where she directs the Culture and Emotion Lab. Her research spans cultural psychology, emotions, and mental health, and her publications include papers in the Journal of Abnormal Psychology, Journal of Personality and Social Psychology, and Cultural Diversity and Ethnic Minority Psychology. Her specific research interests include the cultural shaping of: (a) emotions, including conceptions and functions of emotions, emotional reactivity, and interoception); and (b) social support, including advicegiving and support networks. Her work is supported by the Social Psychology Program of the National Science Foundation.

\section{References}

Achenbach, T. M., \& Edelbrock, C. S. (1983). Taxonomic issues in child psychopathology. In T. H. Ollendick \& M. Hersen (Eds.), Handbook of Child Psychopathology (pp. 65-93). New York: Plenum Press.

Adams, G., Salter, P. S., Pickett, K. M., Kurtis, T., \& Phillips, N. L. (2010). Behavior as mind-in-context: A cultural psychology analysis of "paranoid" suspicion. In L. F. Barrett, B. Mesquita \& E. Smith (Eds.), The Mind in Context (pp. 277-306). New York: Guilford.

Andreasen, N. C. (1997). Linking mind and brain in the study of mental illnesses: A project for a scientific psychopathology. Science, 275, 1586-1593.

Bagby, R. M., Parker, J. D. A., \& Taylor, G. J. (1994). The twenty-item Toronto Alexithymia Scale - I: Item selection and cross-validation of the factor structure. Journal of Psychosomatic Research, 38, 23-32.

Ban, L., Kashima, Y., \& Haslam, N. (2010). Does understanding behaviour make it seem normal? Perceptions of abnormality among Euro-Australians and Chinese-Singaporeans. Journal of Cross-Cultural Psychology. (published online before print, December 15, 2010). doi: 10.1177/0022022110385233.

Barrett, L. F. (2009). The future of psychology: Connecting mind to brain. Perspectives on Psychological Science, 4, 326-339.

Beckstead, Z., Cabell, K., \& Valsiner, J. (2009). Generalizing through conditional analysis: Systemic causality in the world of eternal becoming. $\mathrm{Hu}$ mana Mente: Journal of Philosophical Studies, 11, 65-80.

Bellah, R. N., Sullivan, W. M., Tipton, S. M., Swidler, A., \& Madsen, R. P. (1985). Habits of the Heart. Berkeley: University of California Press.

Betancourt, H., \& López, S. (1993). The study of culture, race and ethnicity in American psychology. American Psychologist, 48, 629-637.

Boorse, C. (1975). On the distinction between disease and illness. Philosophy and Public Affairs, 5, 49-68.

Bruner, J. (1990). Acts of Meaning. Cambridge, MA: Harvard University Press.

Bylsma, L. M., Morris, B. H., \& Rottenberg, J. (2008). A meta-analysis of emotional reactivity in major depressive disorder. Clinical Psychology Review, 28, 676-691.

Cacioppo, J. T. (2007). Psychology is a hub science. $O b$ server, $20,5 \& 42$.

Chentsova-Dutton, Y. E., Chu, J. P., Tsai, J. L., Rottenberg, J., Gross, J. J., \& Gotlib, I. H. (2007). Depression and emotional reactivity: Variation among Asian Americans of East Asian descent and European Americans. Journal of Abnormal Psychology, 116, 776-785.

Chentsova-Dutton, Y. E., \& Heath, C. (2007). Cultural evolution: Why are some cultural variants more successful than others? In M. Schaller, A. Norenzayan, S. J. Heine, T. Yamagishi \& T. Kameda (Eds.), Evolution, Culture, and the Human Mind (pp. 49-70). New York: Psychology Press.

Chentsova-Dutton, Y. E., \& Tsai, J. L. (2010). Self-focused attention and emotional reactivity: The role of culture. Journal of Personality and Social Psychology, 98, 507-519. 
Chentsova-Dutton, Y. E., Tsai, J. L., \& Gotlib, I. H. (2010). Further evidence for the cultural norm hypothesis: Positive emotion in depressed and control European American and Asian American women. Cultural Diversity and Ethnic Minority Psychology, 16, 284-295.

Chiao, J. Y. (2009). Cultural neuroscience: A once and future discipline. Progress in Brain Research, 178, 287-304.

Chiu, C-Y., Gelfand, M. J., Yamagishi, T., Shteynberg, G., \& Wan, C. (2010). Intersubjective culture: The role of intersubjective perceptions in cross-cultural research. Perspectives on Psychological Science, 5, 482-493.

Clark, A., \& Chalmers, D. (1998). The extended mind. Analysis, 58, 7-19.

Cohen, D., Nisbett, R. E., Bowdle, B. F., \& Schwarz, N. (1996). Insult, aggression, and the southern culture of honor: An "experimental ethnography". Journal of Personality and Social Psychology, 70, 945-960.

Cole, M. (1996). Cultural Psychology: A Once and Future Discipline. Cambridge, UK: Cambridge University Press.

Craig, A. D. (2008). Interoception and emotion: A neuroanatomical perspective. In M. Lewis, J. M. Haviland-Jones \& L. Feldman Barrett (Eds.), Handbook of Emotions (3rd ed., pp. 272-290). New York: Guilford Press.

Dere, J., Falk, C. F., \& Ryder, A. G. (2012). Unpacking cultural differences in alexithymia: The role of cultural values among Euro-Canadian and ChineseCanadian students. Journal of Cross-Cultural Psychology., 43(8), 1297-1312.

DeRubeis, R. J., Siegle, G. J., \& Hollon, S. D. (2008). Cognitive therapy versus medication for depression: Treatment outcomes and neural mechanisms. $\mathrm{Na}$ ture Reviews Neuroscience, 9, 788-796.

DiMaggio, P. (1997). Culture and cognition. Annual Review of Sociology, 23, 263-287.

Dion, K. L. (1996). Ethnolinguistic correlates of alexithymia: Toward a cultural perspective. Journal of Psychosomatic Research, 41, 531-539.

Geertz, C. (1973). The Interpretation of Cultures. New York: Basic Books.

Geertz, C. (1984). Distinguished lecture: Anti antirelativism. American Anthropologist, 86, 263-278.

Gilbert, P. (2002). Evolutionary approaches to psychopathology and cognitive therapy. Journal of Cognitive Psychotherapy, 16, 263-294.

Gone, J. P., \& Kirmayer, L. J. (2010). On the wisdom of considering culture and context in psychopathology. In T. Millon, R. F. Krueger \& E. Simonsen (Eds.), Contemporary Directions in Psychopathology: Sci- entific Foundations of the DSM-V and ICD-11 (pp. 72-96). New York: Guilford.

Gotlib, I., \& Hammen, C. (Eds.) (2009), Handbook of Depression, 2nd edition. New York: Guilford Press.

Hacking, I. (1995). The looping effect of human kinds. In D. Sperber, D. Premack \& A. J. Premack (Eds.), Causal Cognition: A Multidisciplinary Debate. Oxford: Oxford University Press.

Hammen, C. (2003). Mood disorders. In I. Weiner (Series Ed.) \& T. Widiger \& G. Stricker (Vol. Eds.), Comprehensive Handbook of Psychology: Vol. 8. Clinical Psychology (pp. 93-118). New York, NY: John Wiley \& Sons.

Heine, S. J., Lehman, D. R., Markus, H. R., \& Kitayama, S. (1999). Is there a universal need for positive selfregard? Psychological Review, 106, 766-794.

Heine, S. J., \& Norenzayan, A. (2006). Towards a psychological science for a cultural species. Perspectives on Psychological Science, 1, 251-269.

Hofmann, S. G., \& Barlow, D. H. (2002). Social phobia (social anxiety disorder). In D. H. Barlow (Ed.), Anxiety and Its Disorders: The Nature and Treatment of Anxiety and Panic (2nd ed, pp. 454-476). New York: Guilford Press.

Hong, Y., \& Chiu, C. (2001). Toward a paradigm shift: From cultural differences in social cognition to social cognitive mediation of cultural differences. Social Cognition, 19, 118-196.

Hong, Y-Y., Morris, M. W., Chiu, C-Y., \& Benet-Martínez, V. (2000). Multicultural minds: A dynamic constructivist approach to culture and cognition. American Psychologist, 55, 709-720.

Hutchins, E. (1995). Cognition in the Wild. Cambridge, MA: MIT Press.

Ilardi, S. S., \& Feldman, D. (2001). The cognitive neuroscience paradigm: A unifying meta-theoretical framework for the science and practice of clinical psychology. Journal of Clinical Psychology, 57, 1067-1088.

Jakobs, E., Manstead, A. S. R., \& Fisher, A. H. (1996). Social context and the experience of emotion. Journal of Nonverbal Behavior, 20, 123-140.

Kashima, Y. (2000). Conceptions of culture and person for psychology. Journal of Cross-Cultural Psychology, 31, 14-32.

Kendler, K. S., Thornton, L. M., \& Gardner, C. O. (2000). Stressful life events and previous episodes in the etiology of major depression in women: An evaluation of the "kindling" hypothesis. American Journal of Psychiatry, 157, 1243-1251.

Kim, H. S., Sherman, D. K., Taylor, S. E., Sasaki, J. Y., Chu, T. Q., Ryu, C., Suh, E. M.; \& Xu, J. (2010a). Culture, serotonin receptor polymorphism and locus of 
attention. Social, Cognitive and Affective Neuroscience, 5, 212-218.

Kim, H. S., Sherman, D. K., Sasaki, J. Y., Xu, J., Chu, T. Q., Ryu, C., Suh, E. M., Graham, K.,\& Taylor, S. E. (2010b). Culture, distress and oxytocin receptor polymorphism (OXTR) interact to influence emotional support seeking. Proceedings of the National Academy of Sciences, 107, 15717-15721.

Kirmayer, L. J. (1987). Languages of suffering and healing: Alexithymia as a social and cultural process. Transcultural Psychiatry, 24, 119-136.

Kirmayer, L. J. (2007). Psychotherapy and the cultural concept of the person. Transcultural Psychiatry, 44, $232-257$.

Kirmayer, L. J. (2012). The future of critical neuroscience. In S. Choudhury \& J. Slaby (Eds.), Critical Neuroscience. Oxford: Blackwell.

Kitayama, S., Markus, H. R., Matsumoto, H., \& Norasakkunkit, V. (1997). Individual and collective processes in the construction of the self: Selfenhancement in the United States and self-criticism in Japan. Journal of Personality and Social Psychology, 72, 1245-1267.

Kitayama, S., \& Park, J. (2010). Cultural neuroscience of the self: Understanding the social grounding of the brain. Social Cognitive and Affective Neuroscience, $5,119-129$.

Kitayama, S., \& Uskul, A. K. (2011). Culture, mind, and the brain: Current evidence and future directions. Annual Review of Psychology, 62, 419-449.

Kleinman, A. (1982). Neurasthenia and depression: A study of somatization and culture in China. Culture, Medicine, and Psychiatry, 6, 117-190.

Kleinman, A. (1988). Rethinking Psychiatry: From Cultural Category to Personal Experience. New York: The Free Press.

Kleinman, A., \& Benson, P. (2006). Anthropology and the clinic: The problem of cultural competency and how to fix it. PLoS Medicine, 3, 1673-1676.

Kleinman, A. M. (1977). Depression, somatization, and the new cross-cultural psychiatry. Social Science and Medicine, 11, 3-10.

Krueger, R. F., \& Markon, K. E. (2006). Reinterpreting comorbidity: A model-based approach to understanding and classifying psychopathology. Annual Review of Clinical Psychology, 2, 111-133.

Lam, K., Marra, C., \& Salzinger, K. (2005). Social reinforcement of somatic versus psychological description of depressive events. Behaviour Research and Therapy, 43, 1203-1218.

Lewis-Fernández, R., \& Kleinman, A. (1994). Culture, personality, and psychopathology. Journal of Abnormal Psychology, 103, 67-71.
Markus, H. R., \& Hamedani, M. G. (2006). Sociocultural psychology: The dynamic interdependence among self systems and social systems. In S. Kitayama \& D. Cohen (Eds.), Handbook of Cultural Psychology (pp. 3-39). New York, NY: Guilford.

Markus, H. R., \& Kitayama, S. (1991). Culture and the self: Implications for cognition, emotion, and motivation. Psychological Review, 98, 224-253.

Marsella, A. J., \& Yamada, A. M. (2010). Culture and psychopathology: Foundations, issues, directions. Journal of Pacific Rim Psychology, 4, 103-115.

Masuda, T., \& Nisbett, R. E. (2001). Attending holistically versus analytically: Comparing the context sensitivity of Japanese and Americans. Journal of Personality and Social Psychology, 81, 922-934.

Matsumoto, D., Takeuchi, S., Andayani, S., Kouznetsova, N., \& Krupp, D. (1998). The contribution of individualism-collectivism to cross-national differences in display rules. Asian Journal of Social Psychology, 1, 147-165.

Mealey, L. (2005). Evolutionary psychopathology and abnormal development. In R. L. Burgess \& K. MacDonald (Eds.), Evolutionary Perspectives on $\mathrm{Hu}$ man Development. Thousand Oaks, CA: Sage Publications.

Nisbett, R. E., \& Cohen, D. (1996). Culture of Honor: The Psychology of Violence in the South. Boulder, CO: West- view Press.

öhman, A., \& Mineka, S. (2001). Fears, phobias, and preparedness: Toward an evolved module of fear and fear learning. Psychological Review, 108, 483-522.

Parker, G., Cheah, Y. C., \& Roy, K. (2001). Do the Chinese somatize depression? A cross-cultural study. Social Psychiatry and Psychiatric Epidemiology, 36, 287-293.

Philippot, P., \& Rimḿ, B. (1997). The perception of bodily sensations during emotion: A cross-cultural perspective. Polish Psychological Bulletin, 28, $175-188$.

Rector, N. A., Kocovski, N. L., \& Ryder, A. G. (2006). Social anxiety and the fear of causing discomfort to others. Cognitive Therapy and Research, 30, 279-296.

Russell, J. A., \& Yik, M. S. M. (1996). Emotion among the Chinese. In M. H. Bond (Eds.), The Handbook of Chinese Psychology (pp. 166-188). Hong Kong: Oxford University Press.

Ryder, A. G., Ban, L., \& Dere, J. (2011). Culture, self, and symptom: Perspectives from cultural psychology. In T. Hansen, P. Berliner \& K. Jensen de Lopez (Eds.), Culture in Self in Mind. Aalborg, Denmark: Aalborg University Press.

Ryder, A. G., \& Dere, J. (2010). Canadian diversity and clin- 
ical psychology: Defining and transcending 'cultural competence'. CAP Monitor, 35, 1 \& 6-13. [Online]. http://cap.ab.ca/pdfs/capmonitor35.pdf (Accessed 16 Sep- tember 2011).

Ryder, A. G., Yang, J., Zhu, X., Yao, S., Yi, J., Heine, S. J., \& Bagby, R. M. (2008). The cultural shaping of depression: Somatic symptoms in China, psychological symptoms in North America? Journal of Abnormal Psychology, 117, 300-313.

Sasaki, J., \& Tanno, Y. (2005). The factor that leads egorrhea symptom to distress in college students. Japanese Journal of Psychology, 76, 397-402. [In Japanese]

Shorter, E. (1992). From Paralysis to Fatigue: A History of Psychosomatic Illness in the Modern Era. New York: Free Press.

Shweder, R. A. (1990). Cultural psychology: What is it? In J. W. Stigler, R. A. Shweder \& G. Herdt (Eds.), Cultural Psychology: Essays on Comparative Human Development (pp. 1-43). New York: Cambridge University Press.

Shweder, R. A. (1995). The confessions of a methodological individualist. Culture and Psychology, 1, 115-122.

Taylor, S. E. (1983). Adjustment to threatening events: A theory of cognitive adaptation. American Psychologist, 38, 1161-1173.

Tseng, W. S. (2006). From peculiar psychiatric disorders through culture-bound syndromes to culture-related specific syndromes. Transcrultural Psychiatry, 43, 554-576.

Uchida, Y., Norasakkunkit, V., \& Kitayama, S. (2004). Cultural constructions of happiness: Theory and empirical evidence. Journal of Happiness Studies, 5, 223-239.

Valsiner, J. (1989). Human Development and Culture: The Social Nature of Personality and its Study. Lexington, MA: Lexington Books.

Vygotsky, L. S. (1978). Mind in Society: The Development of Higher Psychological Processes. Cambridge, MA: Harvard University Press.

Wakefield, J. C. (1992). Disorder as harmful dysfunction: A conceptual critique of DSM-III-R's definition of mental disorder. Psychological Review, 99, 232-247.

Wexler, B. E. (2006). Brain and Culture: Neurobiology, Ideology, and Social Change. Cambridge, MA: MIT Press.

Wiens, S. (2005). Interoception in emotional experience. Current Opinion in Neurology, 18, 442.

Zhang, A. Y., Yu, L. C., Draguns, J. G., Zhang, J., \& Tang, D. (2000). Sociocultural contexts of anthropophobia: A sample of Chinese youth. Social Psychiatry and Psychiatric Epidemiology, 35, 418-426.
Appendix: Practical Recommendations for conducting Cultural-Clinical Psychology Research

\section{Defining Cultural and Diagnostic Categories}

When we use categories, we have a tendency to assume that these categories are clearly separated from one another and capture fundamental differences. We essentialize groups when we assume that all people from a certain cultural background or carrying a certain diagnosis are the same as one another, and different from people in other groups. At the same time, however, it is very difficult to conduct research without relying on groupings of individual people. Researchers should therefore adopt a pragmatic rather than essentialized approach to describing cultural groups and diagnostic categories:

1.1 For cultural groups, specify on a study-by-study basis how each group is defined and for what purposes, and interpret results in light of a more nuanced and dynamic view of culture. Doing so not only means more accurate reporting of methods, but also serves as a reminder that group membership is not self-evident, especially around the edges of a given category.

1.2 For diagnostic categories, consider a 'lumping' approach for syndromes and a 'splitting' approach for symptoms very few broad categories for communication and comparison purposes (e.g., emotional disorders, psychotic disorders) followed by a fine-grained approach to individual symptoms. We might define the problem being compared across groups very broadly - for example, how do people in different context cope with loss? - and then seek to answer that question in part by looking at differences in how individual symptoms are presented.

\section{Understanding and Measuring Culture}

Culture is complex, deeply interconnected with all aspects of human life, often implicit, rarely straightforward, and can shape different people in different ways. It is therefore difficult to study, and it is hard to conduct good research without already knowing a lot about the context being studied - much as mainstream psychology researchers have a lot of tacit and unexamined knowledge about their own contexts. Researchers should therefore know the cultural context well, aided by personal immersion in the context, selected cultural informants, andor multicultural research teams:

2.1 Tell a cultural story about the phenomena under study, aiming to explain ways in which culture shapes mental health rather than cataloguing group differences. At the start of a line of inquiry, that should involve using knowledge of the cultural context to propose potential explanations. Later on, studies should incorporate these potential explanations into the research design; for example, by testing the extent to which they can mediate group difference effects, or by manipulating them experimentally. 
2.2 Pay attention to and assess contradictory cultural scripts, rather than assuming that cultural contexts foster a single script for a particular domain. Doing so helps move away from cultural determinism and helps counteract the tendency to essentialize culture, serving as a reminder that culture is complex and can influence different people in different ways. 2.3 Aim to measure culture in a multi-method way, as it exists in the head (e.g., via self-report or implicit cognitive tasks) and in the world (e.g., via behavioral observation or examination of cultural products). While not always possible within a single study, use of different methods strengthens a line of research and captures some of the complexity of culture. Indeed, it is not always the case that these different methods will agree; points of contradiction may be important.

\section{Situating Research within the Culture-Mind-Brain System}

Situating research within the culture-mind-brain system. We have described culture, mind, and brain as a deeply interactive and non-reductive multilevel system. It is not possible to capture such a system within a single study, or even in a line of research. What is possible, however, is to focus on aspects that are important to the research question and compatible with one's training and resources. These aspects should be identified and studied carefully while we remain mindful that our work is embedded within a broader system. Researchers should therefore remember that a complex and dynamic system requires one to enter at a certain point, chosen for reasons of practicality or training:

3.1 Use culture-mind-brain as the overarching framework, clearly delineating a certain part of the system within a study for pragmatic research purposes. A more narrowlydefined study (e.g., described by the methods and results) can be framed within a broader conceptual argument (e.g., described by the introduction and discussion). A series of more specific empirical papers can be supported by a more general theoretical review.

3.2 Given that one is focusing on part of the system, frame causal arguments as proximal rather than ultimate. It is unlikely that one has identified a causal explanation for anything that itself has no need of explanation. This does not take away from the possibility that we might have identified a crucial link in the causal chain, or the importance of doing so. 